\title{
ESPECIALIZAÇÃO EM BIBLIOTECAS ESCOLARES E ACESSIBILIDADE: DISCUTINDO A GESTÃO DA BIBLIOTECA NA MODALIDADE EAD
}

\author{
ESPECIALIZACIÓN EN BIBLIOTECAS ESCOLARES Y \\ ACCESIBILIDAD: DISCUTIENDO LA GESTIÓN DE LA BIBLIOTECA \\ EN LA MODALIDAD EAD
}

\begin{abstract}
Ariel Behr - behr.ariel@gmail.com Doutorando em Administração, Professor Assistente da Universidade Federal do Pampa (UNIPAMPA), Tutor do Curso de Especialização em Bibliotecas Escolares e Acessibilidade da EBEA/FABICO/UFRGS.

Eliane Lourdes da Silva Moro - eliane_moro@yahoo.com.br Doutoranda em Educação, Professora do Curso de Biblioteconomia da FABICO/UFRGS e Coordenadora do Curso de Especialização em Bibliotecas Escolares e Acessibilidade da EBEA/FABICO/UFRGS.

Lizandra Brasil Estabel - liz.estabel@gmail.com Doutora em Informática na Educação, Professora do Instituto Federal do Rio Grande do Sul, IFRS, e do Curso de Especialização em Bibliotecas Escolares e Acessibilidade da EBEA/FABICO/UFRGS.

Henrique Mello Rodrigues de Freitas - hf@ea.ufrgs.br Pós-doutor, Professor do Programa de Pós Graduação da Escola de Administração da UFRGS, Pesquisador 1 do CNPq.
\end{abstract}

\section{Resumo}

O artigo relata as atividades desenvolvidas em um Curso de Especialização em Bibliotecas Escolares e Acessibilidade da Universidade Federal do Rio Grande do Sul (UFRGS), na modalidade de Educação Aberta e a Distância mediada por computador. Trata de um estudo de casos sobre: qualidade na prestação de serviços em bibliotecas escolares; acesso e uso das tecnologias de informação e comunicação (TICs) como possibilidade de construção de ferramentas de gestão, que auxiliam o bibliotecário a planejar, organizar e avaliar as atividades. Tem como sujeitos da pesquisa alunos do Curso de Especialização que atuavam em três bibliotecas escolares, sendo, respectivamente, uma no Estado do Rio Grande do Sul, uma no Estado da Paraíba; e a terceira no Estado do Rio de Janeiro. Descreve e 
analisa, mais especificamente, os resultados da construção da "Matriz de Priorização GUT" no âmbito das bibliotecas escolares.

\section{Palavras-Chave}

Educação Aberta e a Distância (EAD). Tecnologias de Informação e de Comunicação. Gestão de Biblioteca.

\section{INTRODUÇÃO}

É inegável que o cenário educacional mundial é atualmente permeado por inovações técnicas e didáticas. Um aspecto visível deste avanço pode ser observado na Educação Aberta e a Distância (EAD) que tem substancial adoção em todos os níveis de ensino e treinamento. Esta modalidade de ensino é utilizada integralmente na Universidade Federal do Rio Grande do Sul (UFRGS) nos níveis de extensão, graduação e pós-graduação, porém ainda ganha espaço quando comparada aos cursos presenciais. Com conhecimento desta situação e buscando atender à necessidade de especializar bibliotecários e professores que atuam em bibliotecas escolares, foi proposto o Curso de Especialização em Bibliotecas Escolares e Acessibilidade (EBEA) na modalidade EAD, visando atingir profissionais atuantes não só no estado do Rio Grande do Sul, mas em todo o país. Como parte desta proposta, na estrutura curricular do Curso EBEA, foi distinta a Disciplina "EBEA 004 Gestão e Diretrizes Básicas da Biblioteca Escolar" tratando, dentre outros assuntos, do uso de ferramentas de gestão no contexto da biblioteca escolar, com o objetivo de ampliar as noções gerenciais do papel exercido pelo bibliotecário. Esta fase da proposta surgiu a partir da prática profissional e acadêmica do corpo docente do Curso, e se justificou na experimentação do uso das ferramentas por parte dos alunos da Especialização.

O presente estudo tem caráter qualitativo, caracterizado como Estudo de Caso instrumentalizado por observação participante, não estruturada, realizada em grupo (MARCONI; LAKATOS, 2006). Este instrumento possibilitou a coleta e a análise dos resultados, desde os processos de mediação e de interação, permitindo também o uso das ferramentas do Ambiente Virtual de Aprendizagem (AVA) empregadas no Curso. Como sujeitos, foram selecionados três alunos do Curso EBEA, que aplicaram as ferramentas de gestão apresentadas na Disciplina EBEA 004 em bibliotecas escolares, estando estas em três Estados brasileiros diferentes.

\section{O CONTEXTO DA BIBLIOTECA ESCOLAR}

As bibliotecas escolares apresentam uma realidade de dicotomia no cenário brasileiro, pois enquanto algumas se caracterizam como dinâmicas, atuantes e participativas no processo pedagógico da instituição educacional, outras se apresentam com acervos desatualizados e em condições de precariedade, 
deficiência de mobiliário e equipamento, falta de recursos humanos qualificados, espaço físico insuficiente para acomodação dos usuários, entre outros.

No panorama brasileiro das bibliotecas escolares, o Rio Grande do Sul se diferencia dos demais estados da federação, possuindo o Sistema Estadual de Bibliotecas Escolares (SEBE) presente na Constituição do Estado do Rio Grande do Sul, promulgada em 3 de outubro de 1989, em seu Artigo 218, que prevê a manutenção do SEBE na rede rede pública estadual e a exigência da "existência de bibliotecas na rede escolar privada, cabendo-Ihe fiscalizá-las". Vigora também a Lei Estadual no 8.744 de 09 de novembro de 1988 que prevê, entre outros, recursos do Orçamento do Estado para atualização de acervo e aquisição de mobiliário e equipamento e a obrigatoriedade do horário de leitura em todas as séries de funcionamento do Ensino Fundamental. No entanto, essa realidade é peculiar, pois ainda não está ampliada a imagem da biblioteca como potencial pólo educacional do espaço escolar.

O conceito de biblioteca escolar necessitou superar uma visão tradicional para definir-se em termos modernos como centro ativo de aprendizagem da instituição escolar. Concebe-se a biblioteca escolar como um instrumento de inovação educacional que põe ao alcance dos alunos e professores uma variada gama de materiais educativos, facilitando uma aprendizagem dinâmica e participativa (MORO; NEVES; ESTABEL, 2007).

$\mathrm{Na}$ biblioteca escolar, assim como em outros locais, as Tecnologias de Informação e de Comunicação (TICs), comumente representadas pela internet, contribuem sobremaneira no acesso à informação. Esta última é tida como condição inicial para a aprendizagem, onde o processamento pelo indivíduo, ou seja, sua interpretação e construção de significado, tem a função de transformá-la em conhecimento. Este entendimento é corroborado por Authier (2003) ao reforçar que "o processo de conhecimento é o de buscar soluções para determinados problemas".

Nesta sentido, Castells (1999) diz que a informação, em seu sentido mais amplo, tem sido fundamental em todas as sociedades, e afirma que o paradigma digital fez emergir a Sociedade da Informação e com ela a Sociedade em Rede. Assim colocado, as ferramentas tecnológicas se fazem essenciais na formalização e disseminação do conhecimento, pois segundo o autor, é necessário aliar à tecnologia a capacidade do indivíduo em aprender a captar, gerir, disseminar e aplicar o conhecimento adquirido.

Desta forma, a biblioteca escolar é um ambiente que possibilita aos alunos a captação, a geração, a disseminação e a aplicação dos conhecimentos adquiridos. A biblioteca deve ser a extensão da sala de aula e vice-versa, onde professores e bibliotecários tenham como prioridade estimular o encantamento da leitura e 0 acesso à informação em todos os espaços de vida dos alunos, e onde professores, bibliotecários e pedagogos atuem conjuntamente. 
Com este entendimento, compreende-se que o trabalho da biblioteca não pode ser isolado, sendo fundamental que exista uma relação de colaboração e cooperação para que realmente a biblioteca se torne o coração da escola.

Se acreditamos que a educação pode transformar o nosso país e formar cidadãos, precisamos unir esforços para que as nossas escolas tenham bibliotecas de qualidade, com profissionais preocupados com a formação de leitores e comprometidos com o processo educacional, propiciando aos seus usuários, um ambiente agradável e de aprendizagem (MORO; ESTABEL, 2003).

À luz destas preocupações, percebeu-se a necessidade de oferecer um curso de especialização em bibliotecas escolares alicerçado na EAD, mediado por computador, por ser esta capaz de oferecer um AVA propício à mediação, à construção coletiva, à interação, ao compartilhamento e à troca nas relações entre professores e alunos e, alunos e alunos.

As TICs facilitam a construção do conhecimento permitindo o acesso às fontes de informação, o cruzamento de informação de diferentes fontes e áreas, a comunicação em tempo real ou virtual com outras pessoas e a disponibilização de meios rápidos e eficientes de processamento da informação. Os efeitos do uso da informação compartilhada entre os educadores, os bibliotecários, os alunos, pode encaminhar para uma rede integrada de comunicação, permitindo o estabelecimento de novas relações entre os mesmos (inter-relação de pessoas) e destes com a comunidade.

Assim, a EAD se caracteriza como uma modalidade educacional na qual a mediação didático-pedagógica, nos processos de ensino e aprendizagem, se efetiva com o uso das TICs e com a participação de professores e alunos que realizam atividades de ensino e de aprendizagem em lugares e tempos diversos, como prevê o Decreto № 5.622 (2005) que regulamenta o art. 80 da Lei de Diretrizes e Bases da Educação Brasileira (LDB) e define, no Art. 1ำ a Educação a Distância.

\section{A PROPOSTA DO CURSO DE ESPECIALIZAÇÃO EM BIBLIOTECAS ESCOLARES E ACESSIBILIDADE - EBEA/UFRGS}

Diante da realidade apresentada, a Universidade Federal do Rio Grande do Sul (UFRGS), usando de sua competência para ofertar cursos de extensão, formação, aperfeiçoamento e pós-graduação (lato sensu e stricto sensu), através da Faculdade de Biblioteconomia e Comunicação (FABICO) e do Departamento de Ciências da Informação ( $\mathrm{DCl}$ ) criou o Curso EBEA, visando à atualização e qualificação de professores e bibliotecários que atuem nas bibliotecas das instituições escolares, na modalidade EAD mediado por computador.

No cenário das escolas, embora um significativo número disponha das ferramentas tecnológicas para o ensino e a aprendizagem, preocupa ainda, a falta de 
uma "ação pedagógica digital", que propicie a articulação dos atores (alunos, professores e bibliotecários) na comunidade escolar, através do uso de informações que visam o exercício de sua cidadania e integração social e digital. Entre outros fatores, o acesso à informação, a experimentação do AVA no ambiente da biblioteca escolar, os novos papéis que os educadores assumem no processo de ensino e de aprendizagem, e a busca correta das fontes de informação, auxiliam as atividades desenvolvidas pelos professores nas salas de aula e pelos bibliotecários no espaço da biblioteca escolar, desta forma facilitando a busca de informação e de conhecimento, otimizando o uso das TICs existentes na escola e contribuindo para o benefício coletivo da comunidade escolar.

Assim, a realização do Curso EBEA tem como objetivos principais:

a) qualificar e capacitar os profissionais no âmbito das bibliotecas escolares;

b) propiciar melhoria na qualidade da educação através da Educação Continuada formando o perfil do bibliotecário-educador; capacitar para a utilização de TICs, de uso da Internet e da EAD mediada por computador;

c) instrumentalizar os participantes do Curso para que propiciem: o acesso à informação, a acessibilidade para todos, o uso das TICs, a formação de leitores, o exercício da cidadania e da inclusão social, educacional, digital e informacional à comunidade escolar para a competência informacional;

d) oportunizar a construção dos saberes e o acesso ao conhecimento, contribuindo no processo de ensino e de aprendizagem das instituições educacionais; e

e) qualificar para elaboração e execução de Projetos de bibliotecas acessíveis para a comunidade escolar que propiciem a acessibilidade para todos.

O Curso se desenvolve na modalidade EAD, mediada por computador, estruturado em módulos, prevendo encontros presenciais e a realização de atividades individuais e em grupos, síncronas e assíncronas, no AVA TelEduc que se caracteriza como um ambiente de fácil utilização e possui as seguintes ferramentas: Estrutura do Ambiente; Dinâmica do Curso (informações sobre a metodologia do curso); Agenda (apresentação da programação do curso); Atividades; Material de Apoio; Leituras; Perguntas Frequentes; Parada Obrigatória; Mural; Fóruns de Discussão; Bate-papo; Correio (e-mail); Grupos; Perfil; Diário de Bordo; Portfólio (página individual de cada participante); Acessos (possibilita saber a frequência de acesso dos usuários); Configurar (alteração de senha e seleção de idioma) e Intermap (visualização da interação do grupo), como se pode observar na Figura 1.

Estas ferramentas possibilitam que os alunos adquiram autonomia para a realização das atividades propostas e consigam estabelecer uma relação de comunicação e de interação com os demais componentes do grupo, mediados pelo professor da disciplina e pelos tutores em EAD. O Curso possui uma carga horária de 555 horas/aula, totalizando 37 créditos, tendo início em julho de 2008 e a finalização em marco de 2010 com a apresentação do Trabalho de Conclusão de Curso (TCC) pelos alunos concluintes. 
Figura 1 - Estrutura do AVA TelEduc

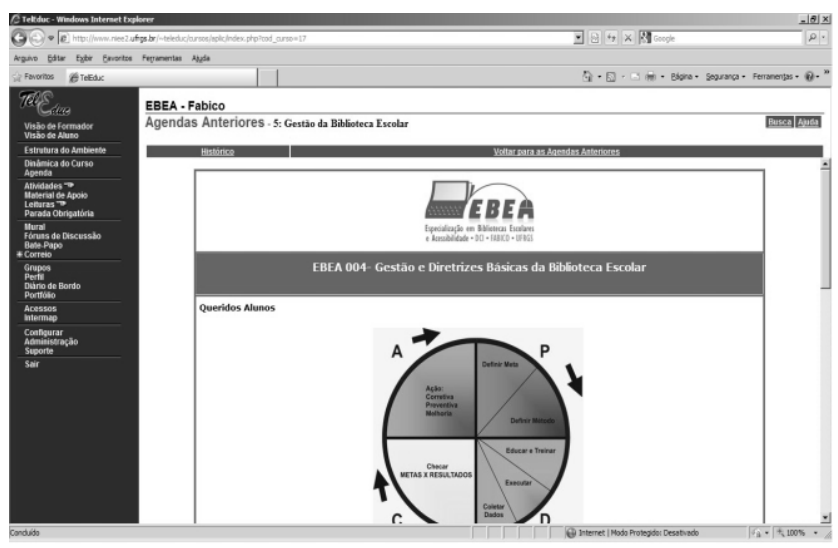

A estrutura do Curso se compõe de oito módulos, organizados em eixos temáticos sendo quatro módulos presenciais e quatro em $E A D$, mediados por computador. Na modalidade presencial realiza-se a avaliação das disciplinas ministradas em EAD, a apresentação das disciplinas em EAD do módulo seguinte e as disciplinas na modalidade presencial. Além disso, são desenvolvidas dinâmicas de grupos, palestras com especialistas da área e visitas de estudo à instituições focadas no desenvolvimento das disciplinas ministradas (Figura 2).

Figura 2 - Apresentação da Estrutura Curricular do Curso EBEA

\begin{tabular}{|c|c|c|c|c|c|}
\hline \multirow{2}{*}{ MÓDULO } & \multirow{2}{*}{$\begin{array}{l}\text { No CRED/ } \\
\text { H AULA }\end{array}$} & \multirow{2}{*}{ DISCIPLINA } & \multirow{2}{*}{ PERÍODO } & \multicolumn{2}{|c|}{ MODALIDADE } \\
\hline & & & & EAD & Presenc \\
\hline \multirow[b]{2}{*}{1} & $1 / 15$ & $\begin{array}{l}\text { EBEA 001- Metodologia da Pesquisa } \\
\text { Cientifica }\end{array}$ & $\mathrm{Jul} / 08$ & & $\mathrm{x}$ \\
\hline & $1 / 15$ & $\begin{array}{l}\text { EBEA 002- Elaboração e Normatização do } \\
\text { TCC-A }\end{array}$ & $\mathrm{Jul} / 08$ & & $\mathrm{x}$ \\
\hline \multirow{3}{*}{2} & $3 / 45$ & $\begin{array}{c}\text { EBEA 003- Bibliotecas Escolares: } \\
\text { competência informacional, acesso e uso das } \\
\text { TICs } \\
\end{array}$ & $\begin{array}{l}\text { Ago/ } \\
\text { Set } 08\end{array}$ & $\mathrm{x}$ & \\
\hline & $3 / 45$ & $\begin{array}{c}\text { EBEA 004-Gestão e Diretrizes Básicas da } \\
\text { BE } \\
\end{array}$ & $\begin{array}{c}\text { Set } \\
\text { Out } 08\end{array}$ & $\mathrm{x}$ & \\
\hline & $2 / 30$ & $\begin{array}{l}\text { EBEA 005-Infomação, Cidadania e } \\
\text { Inclusão Social }\end{array}$ & $\begin{array}{c}\text { Nov/ } \\
\text { Dez } 08\end{array}$ & $\mathrm{x}$ & \\
\hline 3 & $2 / 30$ & $\begin{array}{c}\text { EBEA 006-Gestão da Qualidade Ambiental } \\
\text { em Bibliotecas Escolares }\end{array}$ & Dez 08 & & $\mathrm{x}$ \\
\hline 4 & $2 / 30$ & EBEA 007- Produção de Midias em BEs & $\begin{array}{c}\mathrm{Jan} / \\
\mathrm{Fev} / 09\end{array}$ & $\mathrm{x}$ & \\
\hline \multirow{3}{*}{5} & $3 / 45$ & $\begin{array}{l}\text { EBEA 008-Acessibilidade e Inclusão } \\
\text { Informacional, Social e Digital nas BEs }\end{array}$ & $\begin{array}{c}\mathrm{Mar} / \\
\mathrm{Abr} / 09\end{array}$ & $\mathrm{x}$ & \\
\hline & $3 / 45$ & $\begin{array}{l}\text { EBEA 009-A Mediação da Leitura, a } \\
\text { Formação do Leitor e a Inclusão Social }\end{array}$ & $\begin{array}{c}\mathrm{Abr} / \\
\mathrm{Maio} / 09\end{array}$ & $\mathrm{x}$ & \\
\hline & $3 / 45$ & $\begin{array}{c}\text { EBEA 010- O Processo e o Uso das TICs na } \\
\text { Pesquisa Escolar } \\
\end{array}$ & $\begin{array}{c}\mathrm{Jun} / \\
\mathrm{Jul} / 09\end{array}$ & $\mathrm{x}$ & \\
\hline \multirow[b]{2}{*}{6} & $1 / 15$ & $\begin{array}{l}\text { EBEA 011- Elaboração e Normatização do } \\
\text { TCC-B }\end{array}$ & $\mathrm{Jul} / 09$ & & $\mathrm{x}$ \\
\hline & $2 / 30$ & $\begin{array}{l}\text { EBEA 012-Leitura, ludismo e prazer: o } \\
\text { espaço do brincar }\end{array}$ & $\begin{array}{c}\mathrm{Jul} / \\
\mathrm{Ago} / 09\end{array}$ & $\mathrm{x}$ & $\mathrm{x}$ \\
\hline \multirow{3}{*}{7} & $2 / 30$ & $\begin{array}{l}\text { EBEA 013-Psicologia das Relações entre os } \\
\text { Atores/Sujeitos no Cenário Educacional }\end{array}$ & $\begin{array}{l}\text { Ago/ } \\
\text { Set } 09\end{array}$ & $\mathrm{x}$ & \\
\hline & $3 / 45$ & $\begin{array}{c}\text { EBEA 014- Desenvolvimento de Recursos e } \\
\text { Serviços em BEs }\end{array}$ & $\begin{array}{c}\text { Set } \\
\text { Out } 109\end{array}$ & $\mathrm{x}$ & \\
\hline & $3 / 45$ & $\begin{array}{l}\text { EBEA 015-Prática de Pesquisa em } \\
\text { Bibliotecas Escolares e Acessibilidade }\end{array}$ & $\begin{array}{c}\text { Nov/l } \\
\text { Dez } 09\end{array}$ & $\mathrm{x}$ & \\
\hline 8 & $3 / 45$ & $\begin{array}{l}\text { EBEA 016-Seminário de Integração em } \\
\text { Bibliotecas Escolares e Acessibilidade }\end{array}$ & Dez:09 & & $\mathrm{x}$ \\
\hline TOTAL & $37 / 555$ & 16 Disciplinas & $\begin{array}{c}\text { Jul/08 } \\
\text { Dez/09 }\end{array}$ & 10 & 6 \\
\hline
\end{tabular}


Os alunos participantes do Curso EBEA são na sua maioria graduados em Biblioteconomia e professores com graduação em áreas afins. Na grande maioria estes alunos exercem suas atividades profissionais em bibliotecas escolares e, alguns em bibliotecas universitárias. A modalidade EAD propicia que profissionais residentes em diferentes Estados brasileiros (Paraíba, Bahia, Ceará, Rio de Janeiro, Santa Catarina) e diversos municípios do Estado do Rio Grande do Sul (Farroupilha, Carazinho, Santa Maria, Feliz, Viamão, Cachoeirinha, ljuí e Porto Alegre) realizem as atividades síncronas e assíncronas, em EAD e presencial, sem a necessidade do afastamento, em exercício, nas funções profissionais. Dentre os alunos do Curso EBEA a proposta de acessibilidade transforma-se também em ação inclusiva, pois conta com a participação de uma bibliotecária cega a quem é disponibilizado o acesso e o uso das ferramentas e conteúdos do Curso adaptados ou que sejam acessíveis.

\section{A NECESSIDADE DA DISCIPLINA DE GESTÃO}

A biblioteca, assim como outro serviço qualquer, deve ser gerenciada de maneira sã, buscando atender seus objetivos, e melhorar sempre que possível a qualidade dos serviços prestados. Um princípio de Kaplan e Norton (2004) diz que o que não é medido, não é gerenciado, logo, o que se buscou nesta disciplina da EBEA foi desenvolver no bibliotecário o hábito de mensurar o desempenho do seu trabalho, para posteriormente agir nos pontos vistos como oportunidades de melhoria.

Parte-se do entendimento que as bibliotecas, alvo desta Especialização, fazem parte de uma organização maior: a escola, sendo esta, a responsável por distribuir os recursos julgados necessários para cada atividade. Nesta perspectiva, o papel do bibliotecário, enquanto gestor de um setor que exige muitos investimentos cresce em importância, pois fica a seu juízo captar o que os usuários (alunos, professores e comunidade) precisam para atender suas necessidades de informação e transmitir esta carência da maneira correta ao descentralizador dos recursos. Logo, passa a ser praticamente uma questão "semântica" onde o bibliotecário faz a tradução de "necessidades em investimentos".

Assim, este profissional deixa de ser visto apenas como um gerente de informações e passa a ser visto também como gerente de um ambiente que exige constantes inovações práticas e materiais. Além disso, na escola, onde sensos de justiça e de responsabilidade devem ser promovidos por todas as áreas, mostrar que a necessidade do usuário (seja ele aluno ou professor) é recebida, analisada e divulgada é uma atitude responsável e necessária, desejada a todos os profissionais que atuam em bibliotecas escolares.

O bibliotecário, na gestão de um serviço, tem a necessidade de mensurar o acesso e o uso do acervo através do Serviço de Referência e Informação (SRI). Nesta atividade, deve o bibliotecário atentar no processo de busca, consulta e empréstimo, no tocante à satisfação no atendimento às necessidades informacionais dos usuários, cujos resultados determinarão a eficiência e a qualidade dos serviços 
oferecidos. Desta forma, as ferramentas de gestão "auxiliam o bibliotecário a planejar, organizar e avaliar seus serviços, apresentando resultados que indiquem qualidade nos serviços prestados" (BEHR; MORO; ESTABEL, 2008, p.34).

A grande proposta da disciplina foi então, mostrar ao bibliotecário uma face do seu encargo profissional, responsável por identificar as diversas necessidades de seus usuários, solicitar recursos para atender estas necessidades e prestar contas de suas ações aos gestores da escola e, principalmente, aos usuários da biblioteca.

\section{$5 \quad$ A PROPOSTA DA DISCIPLINA}

A Disciplina é intitulada "Gestão e Diretrizes Básicas da Biblioteca Escolar", com a carga horária de 45 horas/aula perfazendo três créditos, ministrada no Módulo 2 (Figura 2) e tem como súmula o desenvolvimento dos seguintes enfoques: Bibliotecas escolares; Diretrizes da biblioteca no sistema educacional em nível internacional, nacional e regional; Gestão e serviços de bibliotecas escolares. A disciplina tem como objetivos principais: propiciar aos alunos conhecimentos na gestão e serviços de bibliotecas escolares; identificar os atores deste cenário; analisar e discutir as diretrizes da biblioteca no sistema educacional; identificar, analisar e avaliar os produtos e serviços de bibliotecas escolares; propiciar discussões e interação no uso de ferramentas que possibilitem a construção coletiva e compartilhada dos integrantes dos grupos.

A estratégia escolhida para atender a esta proposta foi a elaboração de material didático específico, acessível às Pessoas com Necessidades Especiais (PNEs), com exemplos contextualizados e, que explorasse uma quantidade razoável de ferramentas de gestão, permitindo aos alunos abstrair em um conjunto de aplicações adequado às suas realidades no exercício profissional nas instituições em que atuam.

Desta forma, foi produzido e, posteriormente publicado um artigo científico trazendo oito ferramentas de gestão, apresentando como estas poderiam ser aplicadas no contexto da biblioteca e atendendo critérios de acessibilidade (BEHR; MORO; ESTABEL, 2008, p.34). No desenvolvimento da Disciplina outras ferramentas e exemplos foram evocados, motivados pela necessidade e vivência de cada participante do Curso e estimulados pelas interações nas atividades desenvolvidas e nos problemas identificados no dia-a-dia da gestão da biblioteca escolar.

De acordo com as possibilidades do AVA TelEduc, as atividades foram propostas buscando as avaliações diagnóstica, formativa e somativa dos alunos. Para a avaliação diagnóstica foram realizados, nas atividades síncronas dos batepapos, questionamentos sobre as experiências e problemas relacionados à gestão da biblioteca vivenciados pelos alunos. $\mathrm{Na}$ avaliação formativa foram propostas atividades de leitura, levantamento e identificação de problemas, discussões no Fórum de Discussão, seleção e elaboração de ferramentas de gestão e proposição de soluções a partir destas ferramentas, culminando na publicação de uma atividade individual. E, na avaliação somativa, os alunos realizaram prova presencial onde 
alguns conceitos foram retomados, sendo também consideradas as atividades individuais anteriormente publicadas no AVA TelEduc.

A biblioteca escolar se caracteriza como função pedagógica e abrange ampla "clientela" e de diversos níveis de escolaridade, pois seus usuários pertencem à faixa etária dos dois aos oitenta anos, desde a educação infantil ao pós-médio, incluindo a educação de jovens e adultos, o corpo docente, funcionários e comunidade escolar. O bibliotecário tem a função de gestor e de educador, buscando a oferta de serviços, através da avaliação no uso de ferramentas de gestão, e qualidade, propiciando o acesso e o uso da informação para todos (BEHR; MORO; ESTABEL, 2008, p.32).

Segundo Behr, Moro e Estabel (2008) as ferramentas da qualidade se caracterizam como "instrumentos para identificar oportunidades de melhoria e auxiliar na mensuração e apresentação de resultados, visando ao apoio à tomada de decisão por parte do gestor de determinado processo". Partindo da visão que a biblioteca é uma organização, Freitas et al (1997) deixam ainda mais clara a necessidade da função decisória ao dizerem que a atividade de tomar decisões é crucial para uma organização, pois esta atividade acontece a todo tempo, em todos os níveis, e influencia diretamente na performance da gestão organizacional. Assim, fica evidente que a função do bibliotecário transcende as paredes da biblioteca, e até mesmo da escola, pois suas ações influenciam diretamente a comunidade, que tem em seu acervo e em seu serviço a chave para a informação.

\section{AS POSSIBILIDADES E A UTILIZAÇÃO DO AVA TELEDUC}

A seleção e a escolha de um AVA parte de um planejamento dos educadores responsáveis pela disciplina de acordo com o perfil, as características e as necessidades do grupo, para a realização das atividades síncronas e assíncronas de forma a propiciar a interação, a construção e a autonomia dos alunos. Para que a aprendizagem se realize se faz necessário que os processos de mediação, interação, colaboração e cooperação ocorram e para que se efetivem a escolha das ferramentas de comunicação e de interação do AVA são fundamentais.

Segundo Estabel, Moro e Santarosa (2006) nos AVAs, o papel do educador é o de mediador, propiciando o exercício da colaboração e da cooperação das atividades realizadas, com a participação ativa das situações de aprendizagem propostas, transformando os espaços de sala de aula e da biblioteca em ambientes efetivos de aprendizagem. Nesses ambientes os alunos/usuários tornam-se o centro do processo de ensino e de aprendizagem, tornando-se responsáveis pela sua aprendizagem e co-responsáveis pela aprendizagem do grupo do qual fazem parte.

O AVA também deve contemplar os padrões de acessibilidade permitindo que professores, tutores e alunos possam participar em condições de igualdade. A inexistência de AVAs totalmente acessíveis faz com que a escolha das ferramentas a 
serem utilizadas sejam analisadas e avaliadas previamente para que não ocorra a exclusão das PNEs.

No caso da EBEA, tanto a escolha das ferramentas como a produção de material seguem os padrões internacionais de acessibilidade, possibilitando que a aluna com limitação visual (cega) participe do Curso. Considera-se a participação como sendo a interação com professores, tutores e colegas, o desempenho das atividades com qualidade, e utilização das ferramentas de comunicação e interação como instrumentos nos processos de mediação e interação. Para comprovar esta afirmação, um dos casos deste estudo é justamente a aplicação da ferramenta de gestão pela referida aluna.

A partir da análise e avaliação dos AVAs disponíveis, optou-se pelo uso do AVA TelEduc pois apresentava maior acessibilidade em relação a outros ambientes, sendo possível o acesso através de leitores de telas, softwares utilizados pelas PNEs com limitação visual, que permitem a autonomia no uso dos recursos informáticos por parte do aluno. O AVA TelEduc foi estruturado de forma a possibilitar que a Disciplina "Gestão e Diretrizes Básicas da Biblioteca Escolar" se desenvolvesse propiciando a autonomia dos alunos, sendo estes mediados por professores, tutores e pelos seus pares nos processos de ensino e de aprendizagem.

\section{AS ATIVIDADES DA DISCIPLINA}

A Disciplina iniciou com a apresentação de ferramentas de gestão como instrumentos para identificar oportunidades de melhoria e auxiliar na mensuração e apresentação de resultados, visando o apoio à tomada de decisão por parte dos gestores da biblioteca escolar.

Para que esta apresentação fosse melhor aproveitada pelos alunos, foi proposto como atividade, que cada um identificasse um processo/serviço que necessitasse avaliação na Unidade de Informação. Em seguida, deveriam analisar qual a ferramenta mais adequada para aplicação e quais os serviços e produtos oferecidos poderiam ser avaliados. E, por fim, após este desenvolvimento prático, as atividades deveriam ser publicadas no Portfólio Individual, bem como todo o processo realizado, desde a escolha da ferramenta (justificativa e objetivo), o desenvolvimento e os resultados obtidos através da aplicação desta.

Para auxiliar na realização das atividades, foram indicados dois textos para reflexão e discussão sobre as ferramentas de gestão e serviços exemplificando a aplicação destes no contexto da biblioteca escolar. Uma das dificuldades para o desenvolvimento da disciplina foi a falta e/ou inexistência de referencial teórico sobre o tema proposto com enfoque na biblioteca escolar, o que levou a necessidade da produção escrita de dois textos que atendessem às propostas e aos objetivos do conteúdo programático da Disciplina. Surgiram assim, os dois artigos intitulados: "Gestão da Biblioteca Escolar: metodologias, enfoques e aplicação de ferramentas de gestão e serviços de biblioteca" e "Gestão e Serviços da Biblioteca: uma proposta de atendimento às necessidades de informação dos usuários através do 
Benchmarking e do Sense-making", de autoria de Ariel Behr, Eliane L. da Silva Moro e Lizandra Brasil Estabel.

Foram realizadas duas atividades síncronas através da ferramenta Bate-Papo do AVA TelEduc discutindo sobre a aplicação da ferramenta escolhida pelos alunos e, apresentando outras ferramentas não contempladas na atividade de leitura, como pode se observar no Quadro 1.

Quadro 1 - Recorte do bate-papo tratando "Caixa de Sugestões"

(19:53:56) Ariel fala para Todos: Pessoal, uma ferramenta que não foi abordada e pode ser aplicada facilmente é a Caixa de Sugestão. Basta ter uma caixinha, papéis para receber opiniões e periodicamente coletar as informações, colocar em um quadrinho e apresentar as ações que serão tomadas.

(19:54:46) Ariel fala para Todos: Esse feedback para o usuário aumenta a importância do serviço prestado para ele.

(19:54:48) Eliane Moro fala para Todos: Será que os procedimentos são esses com as várias "Caixas de Sugestões" que as bibliotecas possuem?

(19:55:04) (P) fala para Ariel: Olha só Ariel, boa colocação, como posso saber qual é o problema da nossa, que não colocam as sugestões, onde estou falhando?

(19:55:35) (K) fala para Todos: Ótima idéia Ariel! Eu faço de maneira informal, mas sistematizando fica melhor. Também faço esta coleta para sugestões de novos materiais (livros, periódicos, etc.).

(19:55:39) (EAB) fala para Todos: Nós podemos elaborar ferramentas, então, pois a Caixa de Sugestões é algo que pode ser aplicado de maneira bem eficaz e pode ser pensado por qualquer bibliotecário que deseje melhorar.

(19:55:43) Lizandra fala para Todos: Nossa fundamentação teórica está fundamentada em Vygotsky e acreditamos que o conhecimento se dá em camadas, sedimentado. Portanto, as leituras, a reflexão, a discussão são tão importantes quanto às atividades. Por isso, este tempo anterior à publicação da atividade foi fundamental para vocês realizarem estes processos.

(19:55:50) Ariel fala para $(\mathbf{P})$ : $(P)$, podes melhorar o marketing e o acesso a tua Caixa. (19:55:59) (H) fala para Todos: Muitas vezes as sugestões e/ou críticas que nos incomodam não são consideradas.

(19:56:17) (H) fala para Todos: Isso percebemos em vários setores.

(19:56:42) (P) fala para Ariel: Tipo fazer uma propaganda com cartazes no mural que existe uma caixinha na biblioteca?

(19:57:00) (P) fala para Ariel: Falar com os alunos e professores?

(19:57:05) (H) fala para Todos: O que falta muitas vezes é o retorno ... mesmo para o elogio.

(19:57:28) Ariel fala para $(\mathbf{P})$ : $(P)$, além dessas ações, também podes criar um formulário para sugestões onde fica mais rápida a coleta da informação. Não é a melhor maneira, mas pode ajudar a melhorar a "popularidade" da Caixa.

(19:57:30) (C) fala para Todos: Eu tenho uma caixa de sugestões de compra e ficou cheia.

(19:57:33) (K) fala para Todos: Vou passar de sala em sala - a ETS é pequena - avisando da caixinha!!! Beleza!

(19:57:37) Eliane Moro fala para Todos: Falamos que o usuário é o motivo/foco central dos nossos serviços. Mas em que momento ele tem algum retorno dessa avaliação? A própria direção da instituição, tem acesso aos resultados?

(19:58:05) (EBK) fala para Todos: Gostei desta "caixa de sugestões"

(19:58:23) (H) fala para Todos: Quando eu dava aulas, tínhamos entrevistas com os pais para ouvir críticas e/ou elogios. Chamávamos os pais até para dizer que o filho era um ótimo aluno.

(19:58:33) Eliane Moro fala para Todos: Vi que esta ferramenta será aplicada imediatamente! $[\ldots]$ 
(20:01:00) Eliane Moro fala para Todos: Uma bibliotecária alemã que realizou uma palestra na FABICO, comentando sobre gestão afirmou que de cada dez críticas/sugestões da biblioteca, somente três são positivas ... as negativas são prioridade ... quando o usuário não está satisfeito ele expressa em muito mais intensidade do que quando suas necessidades foram atendidas!

$[\ldots]$

(20:02:23) Lizandra fala para Todos: Não esqueçam que através dos blogs os usuários passaram a ter "voz". Busquem alternativas para que eles expressem a sua opinião.

(20:02:37) Ariel fala para (P): $(P)$, se tu colocares um papel colorido para receber sugestões, e uma caixa bem chamativa, tu já terás usuários atraídos visualmente. E quando tu apresentares o primeiro "cartaz" com soluções adotadas teus acessos aumentarão mais ainda!!!

Fonte: UNIVERSIDADE Federal do Rio Grande do Sul. AVA TelEduc. Bate-papo. 2008.

O e-mail foi outra ferramenta bastante utilizada como atividade assíncrona para os alunos enviarem e esclarecerem suas dúvidas tanto em relação aos textos para leitura como nas etapas de construção da ferramenta. Houve intensa participação no processo de compreensão da aplicação da ferramenta escolhida, e como foco das orientações desta interação, tanto nas atividades síncronas (exemplo da Tabela 1), quanto nos e-mails e comentários das atividades postadas, reforçou-se a importância da prestação de contas aos usuários, sobre as práticas adotadas na biblioteca.

No momento que cada aluno fez sua decisão e escolha da ferramenta que seria utilizada, os professores e tutores passaram a mediar, acompanhar e orientar em cada momento e em cada dúvida que surgia, através de bate-papos, e-mails, fóruns de discussão e comentários no Portfólio do aluno. Em cada etapa da elaboração da ferramenta, as interações entre os alunos, professores, tutores e os próprios colegas se intensificaram resultando em um trabalho em que houve muitas trocas, discussões e compartilhamentos.

\section{SELEÇÃo E CARACTERIZAÇÃo DOS SUJEITOS}

Depois de identificar os problemas que a biblioteca que estava sendo estudada apresentava, alguns alunos selecionaram a ferramenta Matriz de Priorização GUT (BEHR; MORO; ESTABEL, 2008).para realizarem sua atividade de análise. Esta ferramenta prioriza ações a serem adotadas no processo analisado, abordando os aspectos: material, método, mão-de-obra e máquina.

A atividade foi realizada individualmente, pois cada biblioteca escolar dependendo do Estado, da cidade, da graduação de ensino, da localização geográfica, da estrutura administrativa entre outros, apresenta problemas peculiares e diversos. Dessa forma cada aluno deveria refletir, identificar, selecionar tendo como foco a priorização das ações na gestão da biblioteca, analisando a "Gravidade", a "Urgência" e a "Tendência" dos problemas detectados.

As alunas selecionadas neste estudo de caso são três bibliotecárias que residem em Estados diferentes e distantes, geograficamente, um do outro: Rio Grande do Sul, Rio de Janeiro e Paraíba. A ferramenta selecionada pelas três foi a 
Matriz de Priorização GUT com aplicação em biblioteca escolar, sendo que uma das bibliotecárias atua na instituição escolar há mais de dez anos.

A bibliotecária do Rio Grande do Sul teve intensa e ativa participação na atividade síncrona de bate-papo enquanto as outras duas preferiram utilizar as atividades assíncronas para dirimir e esclarecer suas dúvidas iniciais. Cada uma delas selecionou e identificou os problemas decorrentes na sua biblioteca aplicando na ferramenta escolhida (Figuras 3, 4 e 5). As bibliotecas selecionadas são todas do tipo escolar e se apresentam com diferentes características.

\section{Biblioteca escolar situada no Estado do Rio Grande do Sul}

Pertence a uma Instituição Educacional centenária, sendo considerada uma das mais tradicionais do Estado, situada na capital Porto Alegre. A Instituição atende aproximadamente três mil alunos, desde a Educação Infantil ao Ensino Médio. O Colégio possui a biblioteca infantil e biblioteca central com acervo composto de material bibliográfico e digital, de forma a disponibilizar ferramentas e tecnologias para ampliar e qualificar os serviços que oferece aos seus alunos/usuários. Assim, possibilita o acesso e uso das fontes de informação em diferentes suportes, e também disponibiliza acesso ao catálogo online.

Em relação à escolha da ferramenta de gestão, a aluna optou pela aplicação da Matriz de Priorização GUT por concluir que esta era interessante e adequada, por mostrar de forma bem clara o nível de gravidade do problema investigado e o nível de urgência para resolver cada questão. Também levou em consideração que esta ferramenta permite avaliar quais mecanismos podem ser aplicados para solucionar 0 problema, quais das soluções pensadas devem ser priorizadas e o porquê disso.

\section{Biblioteca escolar situada no Estado da Paraíba}

A aluna optou pela Matriz de Priorização GUT, por achá-la mais acessível. A instituição escolar na qual atua se situa na capital da Paraíba, na cidade de João Pessoa, em uma instituição que atende alunos cegos. Esse Instituto realiza um trabalho de extensão em parceria com a Universidade do Estado e um Centro de Estudo de uma Universidade de Sorbonne, em Paris, com atividades de extensão que envolvem diretamente as atividades da biblioteca escolar.

A proposta da aluna, através da ferramenta, era mostrar a situação atual da biblioteca e procurar solucionar, na medida do possível, os problemas encontrados. A biblioteca escolar tem a dependência administrativa ligada a uma organização nãogovernamental, sem fins lucrativos que presta serviços relevantes no âmbito da educação, reabilitação, iniciação desportiva, cultural, pré-profissionalização e socialização de pessoas cegas e com deficiência visual. Mantém-se como uma escola especializada e reconhecida pelo Conselho Estadual, com ensino de $1^{\circ}$ ao $5^{\circ}$ ano do ensino fundamental. Possui cem alunos matriculados em regime de internato, externato e semi-internato. A escola oferece ensino especializado e segue a grade curricular oficial oferecendo atividades na área da reabilitação, as chamadas atividades complementares que garantem mais autonomia e independência para as pessoas cegas viverem em sociedade. 


\section{Biblioteca escolar situada no Estado do Rio de Janeiro}

A aluna não atua diretamente na biblioteca escolar e, por isso, optou em escolher a biblioteca da instituição em que seu filho estuda e não possui profissional bibliotecário. A instituição está localizada em um condomínio de funcionários de uma empresa pública de energia nuclear. Segundo suas observações, a biblioteca escolar não possui política de organização, não tem critério de classificação/indexação, não tem livro tombo ou registro de entrada e saída de material, nem catálogo.

A biblioteca está aos cuidados de uma professora habilitada no curso de Magistério e prestes a se aposentar, sendo esta a única pessoa que consegue localizar os livros quando há alguma solicitação. O espaço físico é pequeno, e não oferece conforto nem climatização. Não tem acesso à internet, os professores não solicitam pesquisas ou trabalhos que sejam realizados na biblioteca e os alunos não frequentam muito o local. A aluna analisou a "Gravidade", a "Urgência" e a "Tendência" dos problemas identificados através da ferramenta, com o objetivo de contribuir à gestão da escola, encaminhando à sua direção os resultados, assim mostrando as necessidades de melhoria de qualidade dos serviços prestados aos alunos e à comunidade escolar.

\section{SELEÇÃo E ANÁLISE dOS CASOS}

Para este artigo, de acordo com a ferramenta de gestão aplicada na atividade entregue, foram selecionadas três atividades de alunos da EBEA. A decisão foi abordar os resultados da Matriz de Priorização GUT, ou simplesmente Matriz GUT, por ser esta uma ferramenta capaz de trazer uma boa noção do contexto analisado. Esta aplicação é uma alternativa para priorizar as ações da gestão, avaliando a gravidade, urgência e tendência dos problemas evidenciados, vindo daí o nome GUT. Estes conceitos são tratados como sendo: gravidade, o impacto do problema nas operações e pessoas envolvidas no processo; urgência, a brevidade necessária para a resolução do problema e; tendência, a apresentação de melhora ou piora do problema. Na Matriz são descritos os problemas e possíveis causas do mesmo, e nas causas são analisadas as três dimensões da ferramenta.

As ferramentas a seguir, apresentam as aplicações dos sujeitos selecionados que tratam de problemas diferentes no mesmo âmbito da biblioteca escolar. Nas figuras 3, 4 e 5 estão dispostas as aplicações das alunas, tratando de três problemas diferentes, que estão no escopo do Curso de Especialização e que são comuns a outras bibliotecas.

A Figura 3 apresenta a Matriz GUT aplicada pela bibliotecária do Rio Grande do Sul. A aluna apresentou como problema o furto e depredação do material bibliográfico do acervo da biblioteca após ter constatado que a cada leitura de estante realizada ocorria aumento no desfalque de material bibliográfico e aumento na quantidade de obras danificadas por usuários; tendo o entendimento das consequências que furtos e danificação acarretam aos serviços da biblioteca. Sendo assim, aplicou a ferramenta de gestão com o objetivo de determinar a prioridade no 
seu atendimento como forma de solucionar o problema verificado. Na dimensão de material foi constatado a partir da aplicação da ferramenta que o furto e a depredação do material acarretam em grande perda financeira para a instituição e ocasionam desfalque grave quando o exemplar é danificado ou furtado e pertence a uma obra em volumes (enciclopédias e diversas obras editadas em volumes), sendo considerados estes problemas de prioridade 1. A perda de material único e não mais reeditado e a impossibilidade de adquirir no mercado apenas o volume danificado/furtado (obras em volumes) são considerados de prioridade 2 causando prejuízo para os seus usuários e para a Instituição. Estes problemas ocorrem também devido a constatação que os escaninhos para guarda de mochilas e sacolas estão localizados no interior da biblioteca, permitindo que os usuários entrem com seus materiais e facilmente possam colocar itens do acervo da biblioteca entre os seus pertences sem que a equipe da biblioteca perceba. Em relação ao item método as prioridades apresentam graus do $4^{\circ}$ ao $8^{\circ}$, sendo que 0 problema de maior prioridade é em relação às reservas, pois para o sistema consta que a biblioteca tem disponível o material para empréstimo, no entanto, após uma leitura de estante se consegue saber das perdas/depredações. Em relação à mão-de-obra foi considerada prioridade 3 a insegurança por parte da equipe da biblioteca de repassar informações aos professores e alunos quanto à quantidade de material/exemplares disponível para empréstimo, pois devido ao problema de furto o sistema pode apresentar que a obra consta no acervo e, no entanto, esta está indisponível. Para a aluna, o fator escassez de pessoal para monitoramento do acervo e usuários tem prioridade 7 e na aplicação da ferramenta apresenta prioridade 1 os fatores do item máquina que poderiam auxiliar na solução dos problemas apresentados: ausência de sistema de monitoramento anti-furto nos livros e ausência de câmeras de vídeo nas dependências da biblioteca. A aluna apresenta que a sua equipe foi qualificada para atuar com os usuários e que o número de profissionais é suficiente para o atendimento. No entanto, seria um custo elevado o investimento em profissionais para efetuarem o controle e a atualização do sistema, sabendo que o monitoramento poderia solucionar este problema.

Figura 3 - Matriz GUT da bibliotecária do Rio Grande do Sul

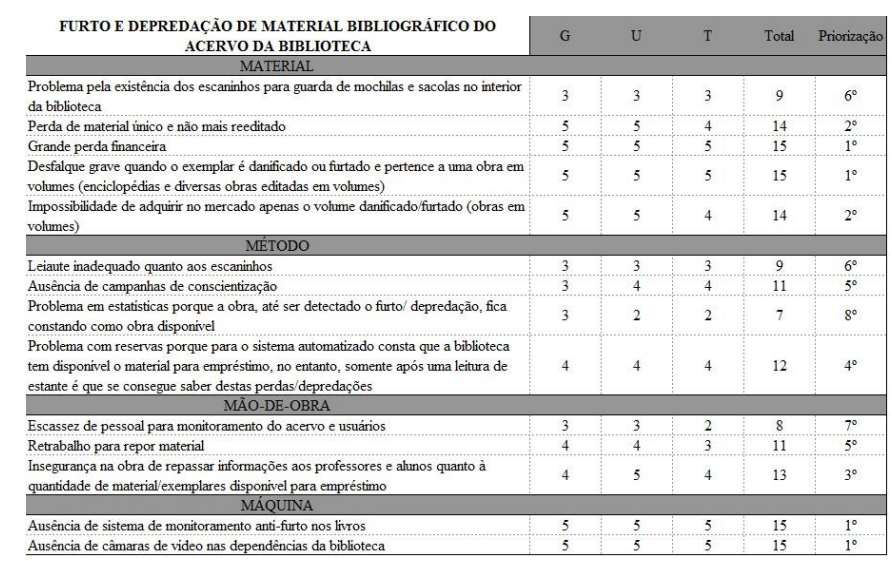


A Figura 4 apresenta a Matriz GUT aplicada pela bibliotecária da Paraíba na Biblioteca onde realiza um projeto de Extensão Universitária. A pontuação estabelecida para cada um dos itens resultou em prioridade na solução dos problemas apresentados.

Figura 4 - Matriz GUT da bibliotecária da Paraíba

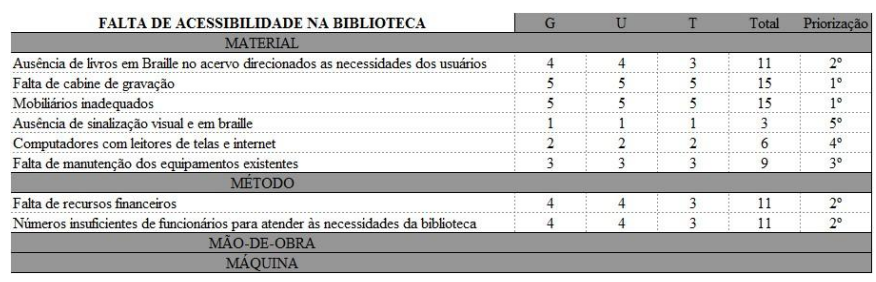

Conforme a aplicação da ferramenta é possível observar que tanto a falta de uma cabine de gravação como a existência de mobiliários inadequados são considerados prioridade 1 na biblioteca na dimensão de material. Como a Instituição atende usuários/alunos com limitação visual, o acesso ao acervo, em muitas situações, se efetiva no acesso e uso dos arquivos sonoros. Inclusive a aluna, ao longo do Curso, desenvolveu atividades através da produção de arquivos em áudio com seus usuários/alunos fazendo uso de recursos de som para realizar as atividades propostas. Portanto, justifica-se a prioridade deste problema inclusive em relação à ausência de livros em Braille no acervo direcionados as necessidades dos usuários, que ficou como prioridade 2. Apesar da Instituição possuir um acervo de qualidade em Braille, atende em parte as necessidades dos usuários. Outro item de prioridade 1 refere-se ao mobiliário sendo este considerado inadequado, fator este que gera desconforto e afasta o usuário da biblioteca, pois não estão adaptados a atender os critérios ergonômicos, de conforto e de acessibilidade. Na aplicação da ferramenta, a falta de manutenção dos equipamentos existentes configura-se como prioridade 3 , pois além de não possuírem recursos financeiros para investimento na aquisição de novos equipamentos, faz-se necessário que seja feita manutenção nos existentes a fim de não prejudicar os serviços prestados aos usuários. A prioridade 4 aponta computadores com leitores de telas e internet já que estes fazem parte do equipamento da biblioteca, sendo mais necessária a manutenção do que a aquisição de novos equipamentos. No entanto, devido a uma maior produção e armazenamento de arquivos em áudio, além da manutenção aos equipamentos é necessária atualização dos mesmos, para maior capacidade de armazenamento de dados, não excluindo a sua função principal no atendimento das necessidades dos usuários.

Como $5^{\text {a }}$ prioridade, a ferramenta indica ausência de sinalização visual e em Braille, tornando-se significativa e importante tendo em vista grande segmento de usuários PNEs, daí a importância da sinalização em Braille para autonomia dos usuários, bem como a visual para os que possuem visão normal incluindo assim as necessidades de todos. Em relação às outras dimensões, os problemas foram agrupados na de dimensão de método, e são apresentados em duas ocorrências: 
falta de recursos financeiros e número insuficiente de funcionários para atender às necessidades da biblioteca, ambos no nível de prioridade 2.

A falta de recursos financeiros é um sério problema enfrentado pelas bibliotecas, mas que pode ser minimizado a partir de ações de marketing, de valorização do espaço da biblioteca junto aos gestores, de busca de parcerias, entre outras ações importantes para a captação de recursos, que inclusive é um dos objetivos da aplicação das ferramentas de gestão. Quanto ao número insuficiente de funcionários, o atendimento ao público é um dos serviços de maior relevância na biblioteca, em especial às que atendem PNEs.

O atendimento ao usuário possibilita que se efetivem os processos de mediação e de referência (atendimento individualizado e de grupo para atender as suas necessidades informacionais), realizados pela equipe da biblioteca. Além disso, é necessário que a equipe seja qualificada para atender as necessidades informacionais do usuário e que tenha conhecimento das tecnologias adaptadas como softwares de voz, ampliadores de telas, entre outros, a fim de orientarem e auxiliarem os usuários com limitação visual no acesso, uso e produção da informação.

Figura 5 - Matriz GUT da bibliotecária do Rio de Janeiro

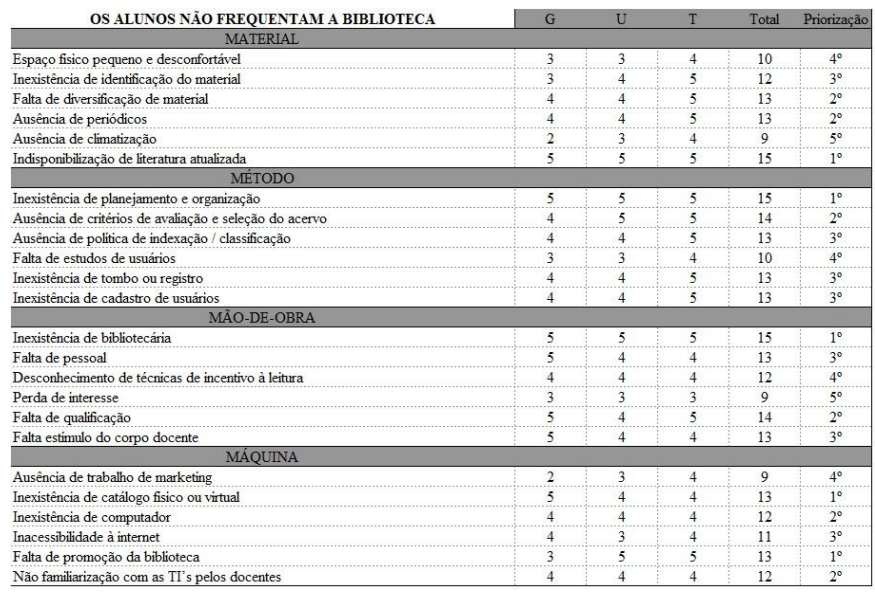

A aplicação da ferramenta pela Bibliotecária do Estado do Rio de Janeiro apresenta cinco prioridades que propiciaram condições à aluna de verificar as carências e necessidades identificadas, mesmo sem atuar como bibliotecária na instituição, tendo somente o vínculo junto à escola, como mãe de aluno do Ensino Fundamental.

$\mathrm{Na}$ dimensão referente ao Material, como prioridade 1, a aluna identificou a indisponibilidade de literatura atualizada, ou seja, a falta e/ou carência de acervo literário atualizado disponível para a leitura e consulta dos usuários da biblioteca. Coincidiram também na mesma prioridade a falta de diversificação de material e ausência de periódicos como prioridade 2 , referindo-se especificamente à ausência de material que é significativo e importante para o processo de ensino e aprendizagem, em que a biblioteca se torna o centro desse processo, auxiliando 
professores e alunos através do material de leitura e de informação atualizados. Na prioridade 3, aparece a inexistência de identificação do material dificultando assim, o acesso aos títulos, autores e assuntos procurados pelos usuários da biblioteca escolar, aumentando também a dedicação e a paciência do professor ou funcionário que atende a biblioteca, quando se faz necessário localizar, em pouco tempo e com qualidade, o material que os usuários solicitam. O espaço físico pequeno e desconfortável caracteriza-se como prioridade 4 mostrando a necessidade de ampliação e normas de conforto ambiental para o oferecimento de um ambiente adequado, aprazível e confortável aos frequentadores da biblioteca escolar. E finalizando este item, na prioridade 5 ausência de climatização vai ao encontro do ambiente confortável, tendo em vista o calor que caracteriza o Estado do Rio de Janeiro, necessitando da climatização para o bem-estar no recinto da biblioteca, além de auxiliar na prevenção do acervo bibliográfico.

Na sequência das análises, a dimensão de Método é a segunda aplicada pela aluna, totalizando mais uma vez seis indicações de prioridades, havendo empate entre três delas. Como prioridade 1 a inexistência de planejamento e organização denota a necessidade de um profissional competente e habilitado para realizar planejamento na organização dos serviços da biblioteca escolar. Na prioridade 2, aparece ausência de critérios de avaliação e seleção do acervo, repercutindo na qualidade e na quantidade de acervo existente e disponível para acesso e uso da comunidade escolar. Como prioridade 3 houve um empate de pontuação no que se refere à gravidade, à urgência e à tendência (GUT) em que aparecem as seguintes prioridades com idêntica pontuação: ausência de política de indexação/classificação; inexistência de tombo ou registro e; inexistência de cadastro de usuários. Estes fatores são essenciais para a eficiência e qualidade dos serviços de atendimento aos usuários e reforçam a necessidade do profissional habilitado. Na prioridade 4 aparece a falta de estudos de usuários que pode ser compreensível e justificável pelas situações apresentadas nos itens e prioridade anteriores.

$\mathrm{Na}$ dimensão de Mão-de-obra apresenta quatro graduações em cinco prioridades. Como prioridade 1 a inexistência de bibliotecária aponta a necessidade da contratação desta "mão-de-obra" especializada para a qualidade dos serviços de gestão. Como prioridade 2 neste item, surge falta de qualificação, referindo-se ao atendimento da biblioteca por pessoas sem a qualificação profissional de bibliotecário. Na prioridade 3 empatam duas prioridades, com a mesma pontuação: falta de pessoal e falta estímulo do corpo docente, constatando-se que além da falta de pessoal qualificado e habilitado na biblioteca escolar, os professores de sala de aula não estimulam os alunos à frequentar a biblioteca, tampouco eles frequentam, denotando que a leitura e a pesquisa escolar, dentre tantas outras atividades que deveriam ser realizadas na sala de aula e na biblioteca não acontecem. A prioridade 4 apresenta 0 desconhecimento de técnicas de incentivo à leitura evidenciando a ausência de profissionais e/ou especialistas de literatura para desenvolver atividades de estímulo a leitura junto aos professores e aos alunos da Instituição. Como prioridade 5 a perda de interesse, denotando a baixa, ou quase inexistente, frequência de usuários da comunidade 
escolar, professores e alunos, uma vez que não há nenhuma ação da biblioteca, ou atendimento adequado que estimule o acesso e o uso.

A última dimensão verificada se refere à Máquina, abrangendo a apresentação de 6 prioridades em 5 graduações, sendo que duas com igual pontuação. A prioridade 1 identifica a inexistência de catálogo físico ou virtual, dificultando a informação do acervo existente na biblioteca escolar. A prioridade 2 apresenta duas necessidades com a mesma pontuação, portanto empatadas: inexistência de computador e a não familiarização com as Tecnologias da Informação (TI) pelos docentes. Este reporte caracteriza e justifica a não frequência dos alunos à biblioteca. A inacessibilidade à internet é tida como prioridade 3, tendo em vista a ausência e/ou inexistência de computadores, e de acesso à internet na biblioteca. As prioridades 4 e 5 apontam, respectivamente, as necessidades de ausência de trabalho de marketing e falta de promoção da biblioteca, ambos em razão da falta de pessoal qualificado, como evidenciado nos itens anteriores.

\section{RESULTADOS}

A análise das três aplicações é de grande valor acadêmico, profissional e social, permitindo na academia, contextualizar os óbices abordados nas diversas disciplinas da EBEA e agregar informações às construções didáticas em qualquer nível de formação de bibliotecários. Na atuação profissional, permite a comparação de realidades, o que é decisivo para a criação compartilhada de significados e soluções. $\mathrm{E}$, no campo social, permite que se verifique a realidade da biblioteca escolar em diferentes pontos do país. Mas não somente a diferença regional é importante no contexto social, pois ainda fatores econômicos, educacionais e legais, da biblioteca e dos usuários, se tornam evidentes nas matrizes vistas e nas análises realizadas.

Além dos resultados evidenciados, a aplicação das ferramentas serve de estímulo aos profissionais que atuam não somente em bibliotecas escolares, mas em qualquer outro tipo de biblioteca. Isto se justifica pois a aplicação de instrumentos que auxiliam a gestão de um ambiente que presta serviços, age diretamente na satisfação inerente aos serviços oferecidos aos usuários, sejam eles do meio escolar ou de qualquer outro meio, melhorando o atendimento às necessidades de acesso e uso da informação. Ademais, a identificação das prioridades, dentro das necessidades do serviços, auxilia o bibliotecário na resolução dos problemas e no estabelecimento de novos enfoques. E cabe reforçar que esta visão não se restringe à gestão da biblioteca, podendo se ampliar à gestão da instituição onde a mesma está inserida.

Enfim, o que se pretendeu trazer neste estudo foi a percepção de que somente de posse dos dados de sua atividade o bibliotecário poderá comparar os serviços prestados com os padrões de excelência estabelecidos. As ferramentas, então, auxiliam o bibliotecário a planejar, organizar e avaliar suas atividades, apresentando os resultados que refletem a qualidade dos serviços que presta. 


\section{CONSIDERAÇÕES FINAIS}

Reveste-se de grande importância o oferecimento de cursos de formação de bibliotecários na área de bibliotecas escolares e acessibilidade, devido à carência de disciplinas nos cursos de Biblioteconomia, que abordem as temáticas de inclusão, acessibilidade, leiaute, uso e acesso a materiais especiais para PNEs, entre outros, além de propiciar a educação continuada de profissionais que atuam em instituições de Educação Básica.

Os profissionais que se formam e atuam no mercado de trabalho tem nas Bibliotecas Escolares um vasto campo de exercício profissional nas instituições de ensino, sejam elas da área pública ou privada. No entanto, inexistem cursos de atualização profissional e de formação do bibliotecário educador. A modalidade de EAD mediada por computador possibilita a participação de bibliotecários, não só do Estado do Rio Grande do Sul (capital e interior), como também, de todos os Estados da Federação Brasileira. Desta forma propicia a troca de experiências, de projetos de trabalho, o compartilhamento e a interação de atividades de aprendizagem e de novos conhecimentos, qualificando ainda mais para o exercício profissional e para a melhoria da Educação Básica das instituições de ensino nos padrões das novas tendências de aprendizagem com tecnologia digital.

Neste contexto, a gestão da biblioteca escolar é um processo primordial na oferta e no desenvolvimento de qualidade em serviços de informação, principalmente no que se refere a metodologias, enfoques e aplicação de ferramentas que auxiliam os bibliotecários a oferecer a informação adequada, no momento certo, tendo em vista que a biblioteca é um organismo em crescimento.

A sociedade da informação e do conhecimento preconiza a integração, reduzindo distâncias, aumentando o nível de informação e, a igualdade no acesso e no uso da informação. Para tal, a aprendizagem possibilita a superação de desigualdades e de exclusão. Por isso, a escola, aonde acorrem milhares de crianças, de adolescentes e de adultos, transforma-se no espaço que propicia a convivência, o compartilhamento, a autonomia e a aprendizagem, ocupando espaços físicos de salas de aulas, de laboratórios e de bibliotecas escolares. Nestas, o bibliotecário que busca a atualização e a especialização para sua competência informacional propiciará aos seus usuários espaços de convivência de aptidões intelectuais e cognitivas, de cidadania e de acesso à informação para todos, através da qualidade dos serviços que presta, sendo estes avaliados constantemente em vistas à construção de um ambiente cada vez mais propício ao conhecimento.

\section{REFERÊNCIAS}


AUTHIER, M. A construção coletiva dos conhecimentos. Revista l-Coletiva. NICE Núcleo de Inteligência Coletiva Aplicada à Educação, n. 11, 27 fev. 2003. Disponível em: < http://www.icoletiva.com.br > Acesso em: 23 set. 2010.

BEHR, A; MORO, E. L. da S.; ESTABEL, L. B. Gestão da biblioteca escolar: metodologias, enfoques e aplicação de ferramentas de gestão e serviços de biblioteca. Ciência da Informação, Brasília, v. 37, n. 2, p. 32-42, maio/ago. 2008.

BRASIL. Leis Decretos, etc. Decreto no 5.622, de 19 de dezembro de 2005. Regulamenta o art. 80 da Lei no 9.394, de 20 de dezembro de 1996, que estabelece as diretrizes e bases da educação nacional. Disponível em: <http://portal.mec. gov.br/setec/arquivos/pdf_legislacao/tecnico/legisla_tecnico_dec5622.pdf> Acesso em: 28 set. de 2010.

CASTELLS, Manuel. A Sociedade em Rede. Trad. Roneide Venâncio Majer. 6. ed. São Paulo: Paz e Terra, 1999.

ESTABEL, L. B.; MORO, E. L. da S.; SANTAROSA, L. M. C. BIBLIOTEC II: o bibliotecário como mediador propiciando a inclusão informacional, social, educacional e digital através da EAD. Informação \& Sociedade: Estudos, João Pessoa, v. 16, n. 2, p. 119-131, jul./dez. 2006.

FREITAS, H. et al. Informação e decisão: sistemas de apoio e seu impacto. Porto Alegre: Ortiz, 1997.

KAPLAN, R. S.; NORTON, D. P. Mapas estratégicos: convertendo ativos intangíveis em resultados tangíveis. Rio de Janeiro: Campus, 2004.

MARCONI, M. A.; LAKATOS, E. M. Técnicas de pesquisa. 6 ed. São Paulo: Atlas, 2006.

MORO, E. L. S.; ESTABEL, L. B. O encantamento da leitura e a magia da biblioteca escolar. Educação em Revista, Porto Alegre, v. 7, n. 40, out. 2003.

MORO, E. L. S.; NEVES, I. C. B.; ESTABEL, L. B. Projeto Especialização em Bibliotecas Escolares e Acessibilidade. Porto Alegre: UFRGS, 2007.

RIO GRANDE DO SUL. Assembléia Legislativa do Estado. Constituição do Estado do Rio Grande do Sul. Art. 218. Disponível em: <http://www.al.rs.gov.br/legis/constituicao.htm>. Acesso em: 28 set. 2010.

RIO GRANDE DO SUL. Assembléia Legislativa do Estado. Lei Estadual n. 8.744 de 09 de novembro de 1988. Cria o plano de expansão da rede de bibliotecas de escolas publicas, estabelece o horário semanal de leitura nas escolas do sistema estadual de ensino e da outras providencias. Disponível em: <http://www.al.rs.gov.br>. Acesso em: 29 set. 2010.

UNIVERSIDADE FEDERAL DO RIO GRANDE DO SUL. AVA TelEduc. Bate-papo. 2008.

\section{Title}


Specialization in School Libraries and Accessibility: discussing the management of the library in distance learning

\section{Abstract}

This article presents a multiple case study conducted with the students of an Open and Distance Learning Program Specialization offered by the Federal University of Rio Grande do Sul (UFRGS) in School Libraries and Accessibility, who work in three different school libraries from three different states of Brazil: Rio Grande do Sul, Paraíba and Rio de Janeiro. An analysis on the quality services in school libraries, and access and use of ICTs was carried on. Also, it investigates the possibility of building management tools for librarians to plan, organize and evaluate the activities, in particular, describing and analyzing the results of construction of the "Matrix Prioritization GUT".

\section{Keywords}

Open Distance Learning. Information and Communication Technologies. Library Management. School Library.

\section{Titulo}

Especialización en Bibliotecas Escolares y Accesibilidad: discutiendo la gestión de la biblioteca en la modalidad EAD

\section{Resumen}

El articulo relata las actividades desarrolladas en un Curso de Especialización en Bibliotecas Escolares y Accesibilidad de la Universidade Federal do Rio Grande do Sul (UFRGS), en la modalidad de Educación Abierta y a la Distancia mediada por ordenador. Tratase de un estudio de casos acerca de la calidad en la prestación de servicios en bibliotecas escolares, el acceso y el uso de las tecnologías de información y comunicación (TICs) como posibilidad de construcción de herramientas de gestión, las cuales ayudan el bibliotecario en el planeamiento, organización y evaluación de las actividades. Tiene como sujetos los alumnos del Curso de Especialización que actuaban, respectivamente, en tres bibliotecas escolares, siendo una en el Estado del Rio Grande del Sur, una en el Estado de Paraíba; y la tercera en el Estado de Río de Janeiro. Describe y analiza, más específicamente, los resultados de la construcción de la "Matriz de Priorização GUT" en el ámbito de las bibliotecas escolares.

\section{Palavras-Chave}

Educación Abierta y a la Distancia (EAD). Tecnologías de Información y de Comunicación. Gestión de Biblioteca. Biblioteca Escolar

Recebido em: 19/01/2011

Aceito em: 11/05/2011 